\title{
RRR Concept and unknown Facts of Ransomware
}

\author{
Ranjitha V.
}

\begin{abstract}
Ransomware is the word which is very popular nowadays. Ransomware is a malicious program that infects the device once it gets into and cannot decrypt the data until the key is provided by the hacker. Ransomware not only forbids the access but also infect the network, where it is communicating with, by encrypting the content that is located on mapped and unmapped network drives where the whole organization networks falls down. In Ransomware various families exist like Cryptoworm, Raas and many. This Ransomware Target is mainly on corporates for beneficial profits. Cryptocurrency is one of the enabling factors of Ransomware. In 2019 according to research work Ransomware raised because of phishing emails and smshing to 109 percent over 2017. Ransomware detections in the first half of the year were up $77 \%$ compared to the latter half of 2018. Around 851 million Ransomware contagious activities happened in 2018. 34\% of corporates came across with this malware and took months or more to recover back and to access their own data. The algorithms that are used by the Ransomware is very complex which cannot be understood by the normal users. This article is to share research findings about Ransomware, some unknown facts where exactly how Ransomware is growing, and also Restrict Recognize React concept (RRR concept) of Ransomware which is mainly for avoiding Ransomware. Restricting is the measures that as to be carried out for avoiding the Ransomware, Recognize is for identifying the Ransomware if device is infected with it, React is mainly responding to the attack to get rid of Ransomware.
\end{abstract}

Keywords : Cryptoworm, Raas, Cryptocurrency, Ransomware, phishing, smshing, RRR concept.

\section{INTRODUCTION}

Ransomware is combination of two words that is ransom and malware where ransom is for money and malware is for infections. For every 14 seconds there is Ransomware attack across the world which leads to the loss $\$ 11.5$ billion by the termination of 2019. Symptoms that mainly victim who got infected by Ransomware will come across is

*Normal Files displays error messages like file is infected when user is trying to open and the file will be with wrong extensions.

*An alert messages with alarming option is placed in desktop background with guidelines for the ransom to recover back the files

*The code is running in the background that scares the user to pay ransom within the deadline otherwise files cannot be decrypted.

*A separate window will be displayed for Ransomware code where victims cannot close it.

*Files will be in the name HOW TO DECRYPT FILES.TXT or

Revised Manuscript Received on February 05, 2020.

* Correspondence Author

Ranjitha V.*, department of Computer Science and Engineering, GITAM School of Technology, Bengaluru, India.

(c) The Authors. Published by Blue Eyes Intelligence Engineering and Sciences Publication (BEIESP). This is an open access article under the CC BY-NC-ND license (http://creativecommons.org/licenses/by-nc-nd/4.0/)
E-mail: ranjithapriu@gmail.com

\section{DECRYPT_INSTRUCTIONS.HTML.[1]}

Figure 1: Shows a sample window how Ransomware really looks. RSA 2048 encryption is basically used by the Ransomware software to encrypt the files.

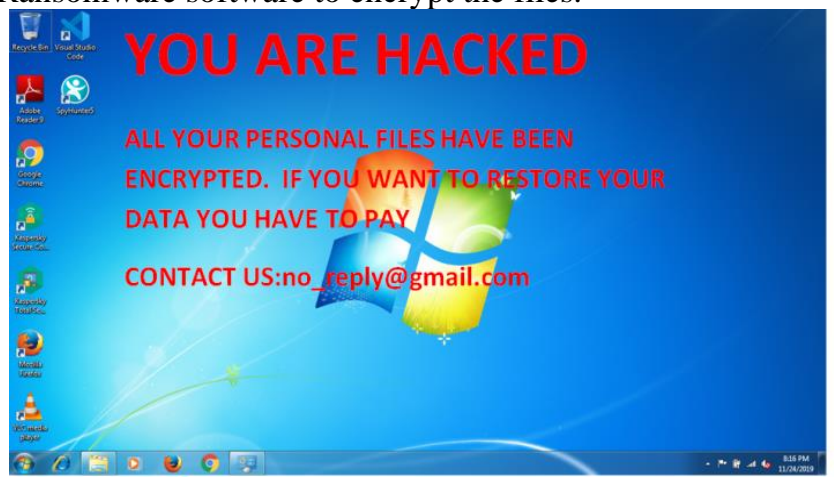

Fig 1: Sample home window with the Ransomware

To know the concept of RSA 2048 key, it is expected 6 quadrillion years to be spent by normal desktop users. For spreading Ransomware Different vectors are used like phishing, smshing, and drive by downloads, free software's and many. To recover from this Ransomware various measures as to be taken like restoring the files from the backup repositories, second is like trying to decrypt the file third is like paying ransoms.

Ransomware types

1) cryptoworm: which grows by replicating until reach the limit

2) Raas: that is Ransomware-as-a service it is a kit available in the markets and the hackers with bad intention can buy it and with less technical knowledge attackers can able to spread it to their targets.

3) Automated Active Adversary - third one where attacker will concentrate on maximum damage that is through automatic scan of internet where attacker knows about the ports which are open to do backdoor entry. [2]

This article is to share knowledge about the Ransomware and to spread knowledge about the risks that suffer will encounter. Paper is divided into the following sections:

The primary section is about background history of malware, countries affected by Ransomware from past 3 years and the recent attacks of 2019-2018 in table form.

The secondary section is workflow of malware exactly how it acts with the victim.

*The third portion demonstrates the various steps genuinely worried in Ransomware after downloading the Ransomware with RRR concept of Ransomware.

*The closing segment suggests the belief information of the Ransomware. [3]

\section{LITERATURE REVIEW}

System files or system where accessed by hacker or attacker via downloading the malicious software called Ransomware from malicious websites by user which later blocks user from accessing his/her own system. 


\section{RRR Concept and unknown Facts of Ransomware}

Entire devices are encoded with attacker's extensions it cannot be decoded until ransom amount is paid. This malware first came into existence in the year 1989 with the "AIDS TROZAN".

Ransomware is popular name from decades where various fields are continuously on research work to completely eradicate Ransomware.

*In 1996 data hijacking was hosted by making use of public key cryptography which was introduced by Adam L. Young and Moti Yung.

The Ransomware actually as various categories like

*Encrypted Ransomware,

*Non-encrypted Ransomware,

*Dox ware,

*Mobile Ransomware.

Each and every category of Ransomware has its speciality and damaging standard in its own way. There are even families of Ransomware like "ACCDFISA, Amnesia, Annabelle, BadRabbit, Bart, Cerber, Cryptolocker, GandCrab, Globe, GlobeImposter, Hermes, HiddenTear, LeChiffre, LockCrypt, Magniber, Nemucod, NotPetya OpenToYou, PCLock, Petya, Rapid, SamSam, Satan, Scarab, SynAck, TeslaCrypt, Troldesh, UIWIX, WannaCry, Xmas, Xoris"

The attackers who constantly involved in this activity are mainly for gaining beneficial profits. It mainly focus on Encrypting the files, spreading around, but nowadays it is with predefined infrastrures that is non-encrypted malware which mainly infects overall and ensures reverseengineering is hectic. Explanation given by Ryan Francis managing editor of CSO and Network World "New-age Ransomware involves a combination of advanced distribution efforts such as pre-built infrastructures used to easily and widely distribute new varieties as well as advanced development techniques such as using crypters to ensure reverse-engineering is extremely difficult."[4]

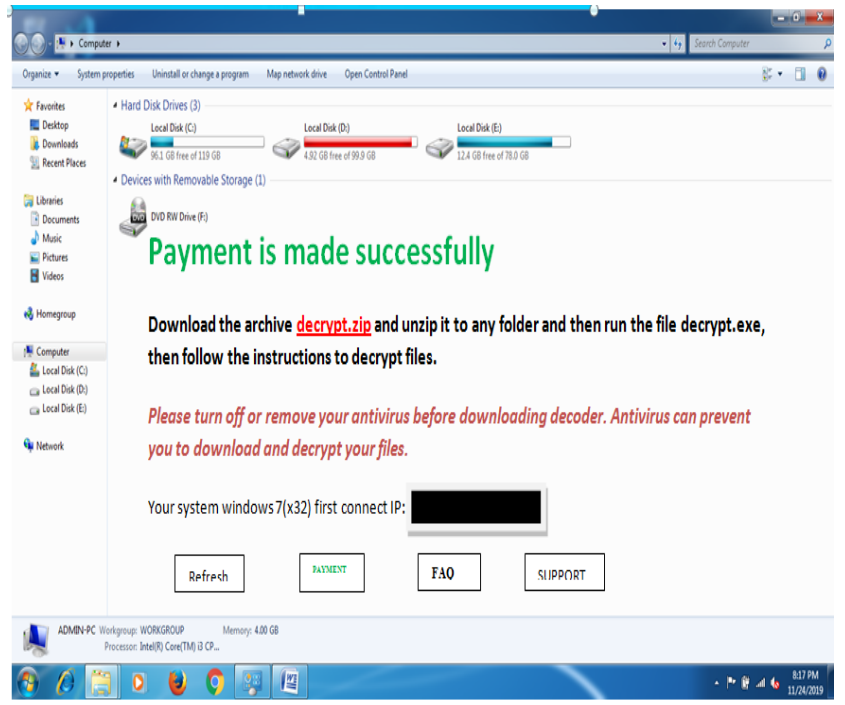

Fig 2: Pattern window of a hit price that is successful payment

Ransomware as global impact that is there are many countries which is facing huge financial loss and where most of the Ransomware affected region are Soudi Arabia, Turkey, china spain south africa and many according to cyber edge shown in the graph.

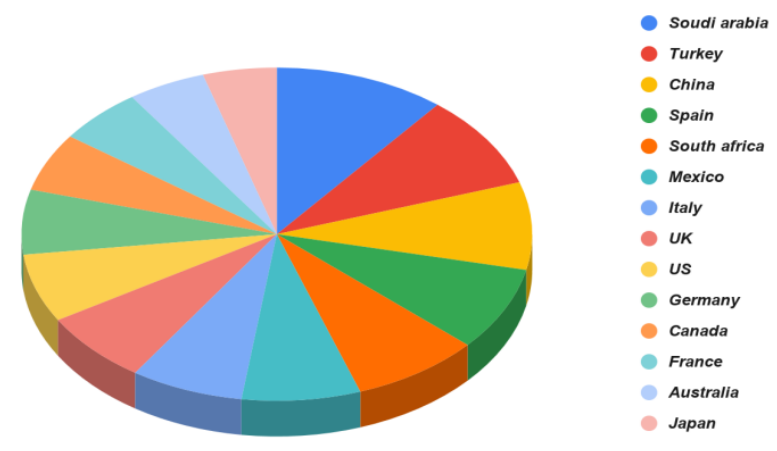

Fig 3: Source from cyber edge which suggests numerous regions suffering from Ransomware in 2018-2019

From the above graph it is virtually recognized that numerous countries are affected by Ransomware and nevertheless they're paying ransoms which is cutting-edge records of November 2018.

But in the year 2017 it's far determined that Spain and China changed into in first location and $2 \mathrm{~d}$ area and plenty of different

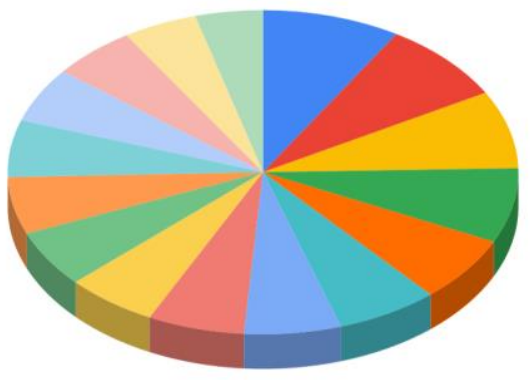

$$
\begin{aligned}
& \text { COuntries. } \\
& \text { Spain } \\
& \text { China } \\
& \text { Mexico } \\
& \text { Soudi Arabia } \\
& \text { Canada } \\
& \text { South Africa } \\
& \text { Italy } \\
& \text { Turkey } \\
& \text { usA } \\
& \text { Brazil } \\
& \text { Singapore } \\
& \text { France } \\
& \text { Coloumbia } \\
& \text { UK } \\
& \text { Australia } \\
& \text { Japan }
\end{aligned}
$$

Fig 4: Various regions laid low with Ransomware in 2017-2018 (source from cyberedge 2018)

From the above graph it is clearly known that various countries are affected by Ransomware and still they are paying ransoms which are latest statistics of November 2018.

Ransomware attack if we are considering in the year 20162017 according to the survey by the cyberedge it is found that various countries had exaggerated are clearly shown fig 5.[5]
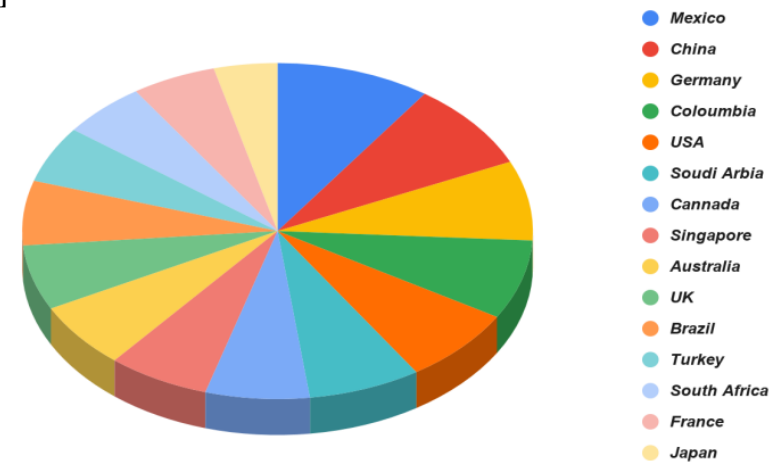

Fig 5: shows the diverse international locations subjected to the Ransomware assault in the year 2016-2017(source from cyberedge 2017) 
Table1:

Details of the Ransomware attack and the form of Ransomware worried in the attack and the targeted countries with year [6]

\begin{tabular}{|c|c|c|c|}
\hline TYPE & YEAR & TARGETED & RANSOM \\
\hline $\begin{array}{l}\text { A kind of } \\
\text { Ransomware }\end{array}$ & $\begin{array}{l}\text { Dec } \\
2019\end{array}$ & New Orleans & $\begin{array}{l}\text { Not disclosed } \\
\text { yet }\end{array}$ \\
\hline MAZE & $\begin{array}{l}\text { Dec } \\
2019\end{array}$ & Pensacola & $\begin{array}{l}\text { Asked to pay } \\
\$ 2.3 \text { million }\end{array}$ \\
\hline Ryuk & $\begin{array}{l}\text { Oct } \\
2019\end{array}$ & $\begin{array}{l}\text { DCH Health } \\
\text { System, a } \\
\text { regional } \\
\begin{array}{l}\text { health } \\
\text { system }\end{array}\end{array}$ & Not disclosed \\
\hline RobbinHood & $\begin{array}{l}\text { May } \\
2019\end{array}$ & $\begin{array}{l}\text { city of } \\
\text { Baltimore in } \\
\text { maryland }\end{array}$ & $\begin{array}{l}\text { Asked for } \\
\text { approximately } \\
\$ 76,200\end{array}$ \\
\hline $\begin{array}{l}\text { Malware from } \\
\text { Email }\end{array}$ & $\begin{array}{l}\text { May } \\
2019\end{array}$ & Riviera Beach & paid $\$ 600,000$ \\
\hline $\begin{array}{l}\text { A kind of } \\
\text { Ransomware }\end{array}$ & $\begin{array}{l}\text { March } \\
2019\end{array}$ & $\begin{array}{l}\text { Jackson } \\
\text { County }\end{array}$ & Paid $\$ 400,000$ \\
\hline SamSam & $\begin{array}{l}\text { April } \\
2018\end{array}$ & city of Atlanta & $\begin{array}{l}\text { Done Ransom } \\
\text { of } \$ 2.6 \text { millions }\end{array}$ \\
\hline
\end{tabular}

\section{PROPOSED METHODOLOGY: RANSOMWARE FLOW}

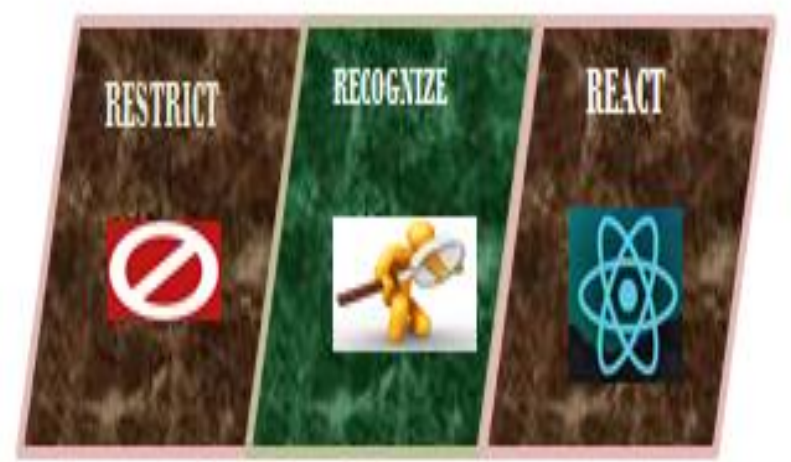

Fig 6: RRR concept blocks

\section{Restrict, Recognize, React or RRR concept( $R 3$ concept)}

Restrict,Recognize,React or R3 concept: It is better to follow $\mathrm{R}$ cube procedure to avoid the Ransomware the first letter $\mathrm{R}$ is for Restrict that is restring or preventing the Ransomware attack, second $\mathrm{R}$ is for Recognize, if system is affected with Ransomware the steps that need to be carried out to analyse what kind of Ransomware got downloaded in the system and the status of the system. Third $\mathrm{R}$ for the react that is after recognizing the Ransomware what steps need to be performed to overcome out of it

Process workflow of Ransomware with flow diagrams can be shown in Fig 7. Through using RRR concept the flow has been considered.

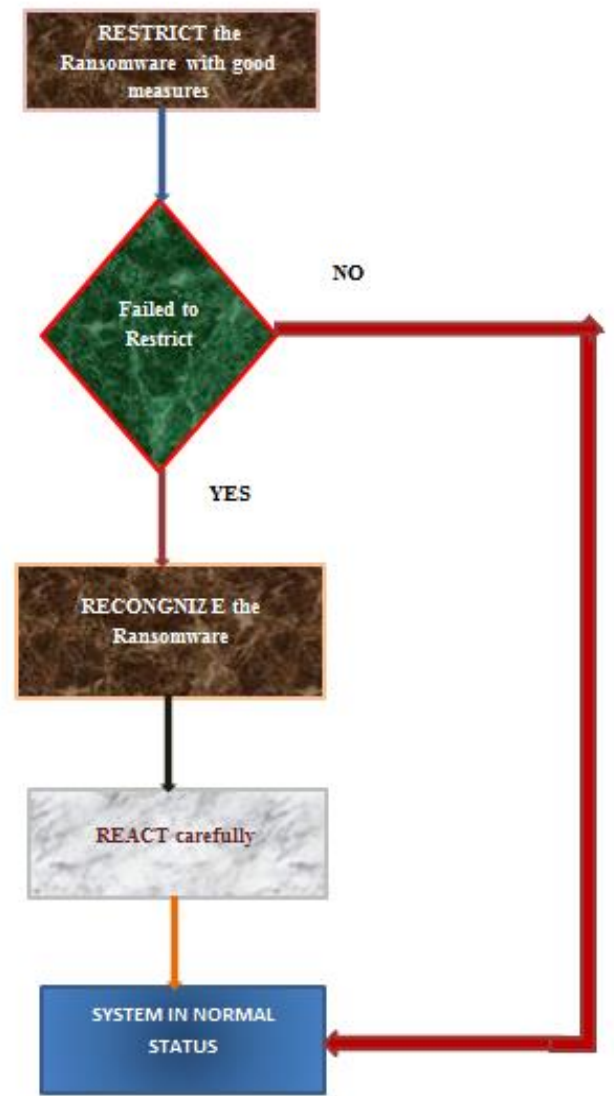

Fig 7: Ransomware Workflow

\section{ALGORITHM}

STEP1: START

STEP2: RESTRICT THE RANSOMWARE WITH CORRECT MEASURES

STEP3: IF (RESTRICTION FAILED) GO TO STEP 4

STEP4: RECOGNIZE THE RANSOMWARE AND THE STATUS OF THE RANSOMWARE, GO TO STEP 5

STEP5: REACT CAREFULLY

\section{STEP6: ELSE SYSTEM IS NORMAL}

\section{STEP 7: STOP}

The workflow of Ransomware actually redirects based on victims actions

1. Users system somehow comes in touch with Ransomware either through phishing activity or in other ways like outdated issues

2. Entire system files is completely encrypted as shown in fig 1

3. After getting infected sufferers will get ransom note for paying the ransom in this step it can be like victim can either pay ransom or not

4. There is a minimum amount of time for paying ransom depending on the attacker. If that deadline exceeds then ransom will be increased in fact it is multiplied.

5. If user pays ransom then decryption key is provided or else functionality of system is lost.

6. If backups are there then sufferers does not pay ransom [7] 


\section{STEPS TO AVOID RANSOMWARE}

RRR concept or ( $R 3$ concept)

\section{RESTRICT}

To avoid Ransomware attack or any other forms of attack several steps need to be followed which mainly comes under first $\mathrm{R}$ that is Restricting Ransomware through following steps

*Avoid opening untrusted website link which usually mislead to an attack where system user he/ she himself will give an authority to the hacker.

*Always system as to be up to date. Any applications and the operating system present in the system should be in current version.

*Always downloads should be from trusty websites where securely downloads should happen that is it should not be from the unreliable links that is like http which is not secured compare to https so always users should go for trusty websites

* Leaking individual's data via untrusted phonecalls, replying to the untrusted mails or through some other means leads to the attack that is either by phishing, smshing, vishing, or through any other social media which mainly contains our activities details leads to the Ransomware attack.

*Careful with emails and messages before opening: Before opening the mail or messages makes sure it is from genuine persons, any case of suspect avoids the mails and messages from opening.

*Content scanning and filtering is a way to avoid mostly the Ransomware where it scans for malware anomalies like Ransomware.

*Before plugging in the other external device to the system scan for virus.

*File integrity monitoring or file internal monitoring this procedure helps in monitoring the files if any changes in the files happen then alert messages is given to system admin.

*System as to be with regular backup in order to safeguard the data.

*System as to be with strong passwords.

*Virtual private networks help primarily in using public wifi and that avoids Ransomware.

* Most of the times antivirus software, firewall and the Internet security even avoids the Ransomware.

*Traffic monitoring that takes place on a daily basis need to be monitored only to avoid or block the initial attack.

*By monitoring log user can identify the traces of attacker if attacker is targeting the system for Ransomware attack.

*Create Restore points and recovering points from system control panel settings which mainly assists in recovery.

*Network segmentation (private networks) to avoid infected shares or critical computers and to protect genuine data present in the system.

*Users who are using the system should not be given with admin rights when they are not required.

*Creating awareness by educating employees, family friends about the Ransomware attack and the consequences of it.

There are even tools that restrict Ransomware from the attack this tools as various layers of security in 2019 this are tools which are making sounds in the society.[8]
Table 2: TOOLS of 2019 that are restricting Ransomware to maximum extent.

\begin{tabular}{|c|c|c|c|}
\hline $\begin{array}{l}\text { SL. } \\
\text { NO. }\end{array}$ & LOGO & $\begin{array}{l}\text { FULL } \\
\text { FORM }\end{array}$ & GOAL \\
\hline 1 & & $\begin{array}{l}\text { Acronis } \\
\text { Ransomware } \\
\text { Protection }\end{array}$ & $\begin{array}{l}\text { Acts upon type } \\
\text { of } \\
\text { Ransomware } \\
\text { like wannacry, } \\
\text { petya, Osiris, } \\
5 G B \text { of data } \\
\text { can be } \\
\text { protected }\end{array}$ \\
\hline 2 & & $\begin{array}{l}\text { Avast Free } \\
\text { Antivirus }\end{array}$ & $\begin{array}{lr}\begin{array}{lr}\text { Avast } \\
\text { remove }\end{array} & \begin{array}{r}\text { can } \\
\text { the }\end{array} \\
\text { threats } & \text { to } \\
\text { maximum } & \\
\text { extent. } & \text { Six } \\
\text { layers } & \text { of } \\
\text { security } & \text { to } \\
\text { catch } & \\
\text { Ransomware } \\
\end{array}$ \\
\hline 3 & & $\begin{array}{l}\text { Bitdefender } \\
\text { GravityZone }\end{array}$ & $\begin{array}{lr}\text { End points } \\
\text { Security for } \\
\text { threat } \\
\text { avoidance }\end{array}$ \\
\hline 4 & & $\begin{array}{l}\text { Check Point } \\
\text { SandBlast } \\
\text { Agent }\end{array}$ & $\begin{array}{l}\text { Protecting } \\
\text { from } \\
\text { Ransomware } \\
\text { attack by } \\
\text { sidestepping } \\
\text { the } \\
\text { convolution } \\
\text { network } \\
\text { making } \\
\text { organization } \\
\text { isolated. }\end{array}$ \\
\hline 5 & & $\begin{array}{l}\text { Cisco } \\
\text { Ransomwar } \\
\text { e Defense }\end{array}$ & $\begin{array}{l}\text { Protecting } \\
\text { from DNS to } \\
\text { email to End } \\
\text { point where } \\
\text { Ransomware } \\
\text { attack is more. }\end{array}$ \\
\hline 6 & & $\begin{array}{l}\text { Commvault } \\
\text { Ransomwar } \\
\text { e Protection }\end{array}$ & $\begin{array}{l}\text { This protection } \\
\text { can give alerts } \\
\text { to the company } \\
\text { when } \\
\text { Ransomware } \\
\text { attacks happen } \\
\text { so that } \\
\text { company can } \\
\text { react faster for } \\
\text { it. }\end{array}$ \\
\hline
\end{tabular}




\begin{tabular}{|c|c|c|c|}
\hline 7 & & $\begin{array}{l}\text { Kaspersky } \\
\text { Anti- } \\
\text { Ransomwar } \\
\text { e Tool }\end{array}$ & $\begin{array}{l}\text { Scanning } \\
\text { cloud to block } \\
\text { the } \\
\text { Ransomware } \\
\text { immediately } \\
\text { and gives the } \\
\text { protection } \\
\text { from } \\
\text { WannaCry, } \\
\text { Petya, Bad } \\
\text { Rabbit, Locky } \\
\text { and } \\
\text { TeslaCrypt. }\end{array}$ \\
\hline 8 & & $\begin{array}{l}\text { Malwarebyt } \\
\text { es Premium }\end{array}$ & $\begin{array}{l}\text { It provides } \\
\text { protection for } \\
\text { the operating } \\
\text { systems like } \\
\text { MAC, } \\
\text { ANDROID } \\
\text { etc., It also } \\
\text { warns the user } \\
\text { when user } \\
\text { accidentally } \\
\text { visits the } \\
\text { website }\end{array}$ \\
\hline 9 & dall|lel & $\begin{array}{l}\text { Symantec } \\
\text { Endpoint } \\
\text { Protection }\end{array}$ & $\begin{array}{l}\text { It detects the } \\
\text { Ransomware } \\
\text { malware and } \\
\text { also it searches } \\
\text { for the other } \\
\text { threats with the } \\
\text { assistance of } \\
\text { machine } \\
\text { learning }\end{array}$ \\
\hline 10 & Antikansomwave & $\begin{array}{l}\text { Trend } \\
\text { Micro Anti- } \\
\text { Ransomwar } \\
\text { e Tools }\end{array}$ & $\begin{array}{l}\text { It is an } \\
\text { intelligent } \\
\text { technology } \\
\text { that generally } \\
\text { applies the } \\
\text { required } \\
\text { methodology } \\
\text { at the right } \\
\text { time. }\end{array}$ \\
\hline
\end{tabular}

\section{RECOGNIZE}

If System is affected with Ransomware because of system Admin who failed to avoid the attack the following symptoms as to be observed by the sufferers to know that they under attack, Indications like

1) ENCRYPTION,

2) RENAME of files,

3) WINDOWS wallpaper display,

4) Multithreaded tasks and many.

The kind of Ransomware that hit the system can be of various variants of Ransomware which as its own specialty of spreading.[9]

Table 3:

There are few Ransomware kinds which are very lively in 2019[2]

\begin{tabular}{|l|l|l|}
\hline Sl.No. & Type & FUNCTIONALITY \\
\hline 1 & STOP(DJVU) & $\begin{array}{l}\text { It locks the system } \\
\text { content and main } \\
\text { targets are the home }\end{array}$ \\
\hline
\end{tabular}

\begin{tabular}{|c|c|c|}
\hline & & $\begin{array}{l}\text { users when they } \\
\text { download unsecure } \\
\text { files from torrents }\end{array}$ \\
\hline 2 & DHARMA & $\begin{array}{l}\text { Instructions will be } \\
\text { provided in order to } \\
\text { contact hacker to } \\
\text { pay ransom by } \\
\text { locking the system }\end{array}$ \\
\hline 3 & PHOBOS & $\begin{array}{lr}\text { Spreads } & \text { from } \\
\text { unsecure } & \text { remote } \\
\text { Desktop protocol } \\
\text { ports same } & \text { as } \\
\text { Dharma } & \text { gives } \\
\text { guidelines } & \text { to } \\
\text { contact hacker } & \end{array}$ \\
\hline 4 & $\begin{array}{l}\text { GLOBELMPOSTE } \\
\mathrm{R}\end{array}$ & $\begin{array}{l}\text { Its next variant of } \\
\text { above type, make } \\
\text { use AES 256 to } \\
\text { encrypt files }\end{array}$ \\
\hline 5 & REVIL & $\begin{array}{l}\text { First discovered in } \\
2019 \text { also called as } \\
\text { sodinokibi and uses } \\
\text { very advanced } \\
\text { technique to escape } \\
\text { from the software }\end{array}$ \\
\hline 6 & GANDCRAB & $\begin{array}{l}\text { It infects and } \\
\text { encrypts all files } \\
\text { within the system } \\
\text { and also it is from } \\
\text { various exploit kits. }\end{array}$ \\
\hline 7 & MAGNIBER & $\begin{array}{l}\text { Encryption of file } \\
\text { happens where each } \\
\text { file is encrypted } \\
\text { with a different key, } \\
\text { And files are with } \\
\text { different cipher text }\end{array}$ \\
\hline 8 & SCARAB & $\begin{array}{l}\text { It makes use of } \\
\text { emails to get into } \\
\text { system as a group of } \\
\text { malware. }\end{array}$ \\
\hline 9 & RAPID & $\begin{array}{l}\text { Once system gets } \\
\text { infected the } \\
\text { malware tries to } \\
\text { remove windows } \\
\text { copy volume and } \\
\text { also stops database. } \\
\text { It encrypts all files } \\
\text { and issues ransom } \\
\text { bill }\end{array}$ \\
\hline 10 & TROLDESH & $\begin{array}{l}\text { Other name is shade } \\
\text { account spreads } \\
\text { through zip files } \\
\text { which is Javascript } \\
\text { encrypt the files }\end{array}$ \\
\hline 11 & WANNACRY & $\begin{array}{l}\begin{array}{l}\text { Main target is the } \\
\text { systems } \\
\text { windows with } \\
\text { operating system }\end{array} \\
\end{array}$ \\
\hline
\end{tabular}




\section{RRR Concept and unknown Facts of Ransomware}

\begin{tabular}{|c|c|c|}
\hline 12 & SAMSAM & $\begin{array}{l}\text { Single threaded it } \\
\text { decrypts at most one } \\
\text { document at a time } \\
\text { came in to existence } \\
\text { in } 2015 \text { most } \\
\text { overwhelming }\end{array}$ \\
\hline 13 & BITPAYMER & $\begin{array}{lr}\text { Single } & \text { threaded, } \\
\text { Knows to } & \text { abuse } \\
\text { alternate } & \text { data } \\
\text { streams } & \\
\end{array}$ \\
\hline 14 & RYUK & $\begin{array}{l}\text { Multithreaded at a } \\
\text { time many files are } \\
\text { encrypted even } \\
\text { network drives }\end{array}$ \\
\hline 15 & LOCKERGOGA & $\begin{array}{l}\text { Which reduces the } \\
\text { antimalware } \\
\text { detection system } \\
\text { efficiency, single } \\
\text { threaded does not } \\
\text { encrypt network } \\
\text { drives }\end{array}$ \\
\hline 16 & MEGACORTEX & $\begin{array}{l}\text { Renames the } \\
\text { document before } \\
\text { encrypting the file, } \\
\text { it as a dynamic link } \\
\text { library of } 32 \text { bit, } \\
\text { single threaded }\end{array}$ \\
\hline 17 & ROBBINHOOD & $\begin{array}{l}\text { It make use Sample } \\
\text { SHA-256 }\end{array}$ \\
\hline 18 & SODINOKIBI & $\begin{array}{l}\text { Distribution is } \\
\text { Through malspam } \\
\text { that is malware zip } \\
\text { is from emails to } \\
\text { systems }\end{array}$ \\
\hline
\end{tabular}

All listed Ransomware make use of SHA-256 with various indications like

\section{- WannaCry}

ED01EBFBC9EB5BBEA545AF4D01BF5F10716618404

80439C6E5BABE8E080E41AA

- GandCrab

6FBA19BF0CC1BB764E063C1DE51CAF0CF0A6CC90

FA76B592BCDE28CEEE161BDC

- SamSam

8C0425ECA81E1EEAF8043764EB38A2BC103598163D

3307E583F4E5AD7EB0E708

- Dharma

B8D32ED92E3227836054ED6BB4E53AD2E0ABE4617

F1215D5E81162F9F5513EC2

- BitPaymer

655C44BEBB2A642E665316236A082C94F88A028721C

19BD28B5F25E1C40A13B8

- Ryuk

830F83578F3A5593B103EA4A682788DC376E96247CD 790417F2630884D686E9F

- LockerGoga

2CE4984A74A36DCDC380C435C9495241DB4CA7E10 7FC2BA50D2FE775FB6B73CE

- MegaCortex F5D39E20D406C846041343FE8FBD30069FD50886D7 D3D0CCE07C44008925D434

- RobbinHood 3BC78141FF3F742C5E942993ADFBEF39C2127F9682 A303B5E786ED7F9A8D184B
- Sodinokibi

06B323E0B626DC4F051596A39F52C46B35F88EA6F85 A56DE0FD76EC73C7F3851[3][14-15]

\section{REACT}

Once sufferers found that he has been infected by the Ransomware the steps that victim should follow which comes under Reacting process are

1) FREE EVERYTHING

*As soon as recognizing the attack makes sure that the system is isolated from the network.

*off the all wireless functionalities which are running in the background like Wi-Fi, Bluetooth etc.

\section{*SEPTICITY RANGE AS TO BE IDENTIFIED}

Checking whether the devices like USB drives, files, and folders have been encrypted or not only to know that to what extent has the infection been spread.

*RECOGNIZE

Identifying which type of Ransomware has been affected to the system eg:DHARMA which is listed in the recognizing procedure[10]

\section{REACT}

1) BRING BACK FROM THE BACKUP

If person as good backup of data then not to worry documents that person wanted, can get back from cloud garage,

Second manner of reacting is

2) TRYING TO DECRYPT THE ENCRYPTED FILE

Applying all sense of decryption intelligence and getting back the content material is very difficult due to complex algorithms that are used for encryption.

2) DO ZERO

Instead of doing many complicated tasks to get information back and knowing which could be very hard to do, sufferers no need to do anything no longer to pay even Ransom additionally.

3) PAYING RANSOM

Next method is paying ransom where either with the aid of negotiation or via paying entire ransom as soon as sufferers pay fig 2 sample is displayed

4) PROTECTING FROM FUTURE

Protecting the device completely from the Ransomware and every other attack with the help of safety stuff which are referred to within the Restrict procedure [11-13]

Third manner is

Contact cyber security professionals, who can help in deciding the best manner to continue and may be Capable of lend free technical information important to analyze and clear up the annoyance. A few Corporations that inspect and offer this steering include: Center for Internet Security's (CIS) Multi-State Information Sharing \& Analysis Center [14-15]

\section{RESULT ANALYSIS}

As according to the RRR concept awareness among the users reduces the total number of attacks here is sample window shown in the graph where $\mathrm{Y}$ axis is with attacks taken in thousands and $\mathrm{X}$ axis is with RRR and without RRR concept, so with RRR concept less number of attacks is seen. 


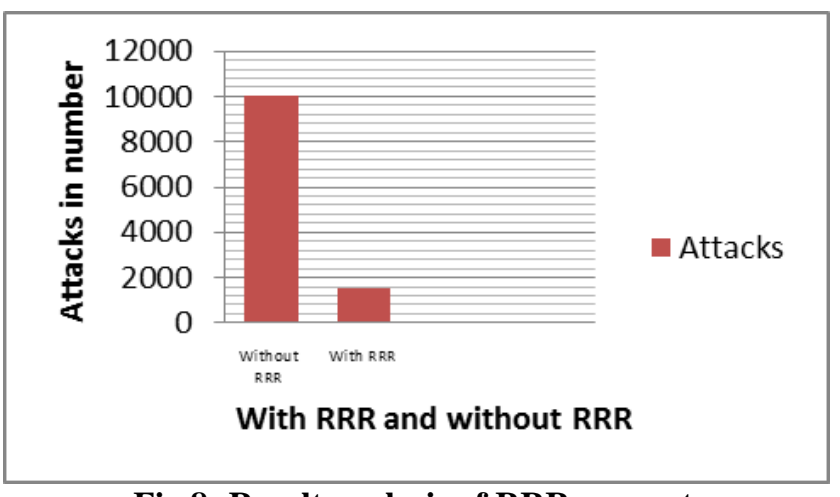

Fig 8: Result analysis of RRR concept

\section{CONCLUSION}

This paper gives idea regarding many unknown factors of Ransomware where it created its footprints in many regions of the continent and they are financially affected, the process flow of the Ransomware program and various paths that victims takes based on the criteria they have, and the steps that mostly avoids the Ransomware like RRR acronym, that provides the knowledge like always system as to be up to date, Scan before plugging in the other external device to the system, and backup for data and many.

\section{LIMITATION AND FUTURE WORK}

There are few strategies to stop this Ransomware like predictive models and collecting human responses but it could do approximately, however there are gap environs in completely abolishing this Ransomware.

\section{REFERENCES}

1. 2019 State of Malware-Malwarebyte resources page no.20-22

2. McAfee Labs Threats Report August 2019 given by MCAFEE labs.

3. RANSOMWARE Hostage Rescue Manual 2019-hubspot

4. Muhammad Ubale Kiru,Aman B. Jantan"The Age of Ransomware: Understanding Ransomware and Its Countermeasures".

5. Gavin Hull1, Henna John2 and Budi Arief3'Ransomware deployment methods and analysis: views from a predictive model and human responses".

6. Ransomware on the Rise But with OneXafe Never Pay the Ransom 2019

7. Nihad A. Hassan'Ransomware Revealed A Beginner's Guide to Protecting and Recovering from Ransomware Attacks"

8. Mihail Anghel, Andrei Racautanu "A note on different types of Ransomware attacks" page no. 3

9. Mark Loman, Director, Engineering," How Ransomware Attacks", Sophos 2019

10. New York State Comptroller THOMAS P. DiNAPOLI "Local Government Management Guide Ransomware"

11. Kruse, Clemens Scott* | Frederick, Benjamin | Jacobson, Taylor | Monticone, D. kyle,"Cybersecurity in healthcare: A systematic review of modern threats and trends",Technology and Health Care, vol. 25, no. 1, pp. 1-10, 201, page no.5-6

12. Volume 14, 2017 Accepting Editor: Eli Cohen $\mid$ Received: November 29, 2016 | Revised: January 18, March 2, 2017 | Accepted: March 28, 2017. Cite as: Ali, A. (2017). Ransomware: A research and a personal case study of dealing with this nasty malware.

13. "I was told to buy a software or lose my computer. I ignored it": A study of Ransomware Camelia Simoiu Stanford University Christopher Gates Symantec Joseph Bonneau New York University Sharad Goel Stanford University

14. From the internet cyber edge source https://cyber-edge.com/wpcontent/uploads/2018/03/CyberEdge-2018-CDR.pdf,https://cyberedge.com/wp-content/uploads/2017/03/CyberEdge-2017-CDRreport.pdf

15. A note on different types of Ransomware attacks Mihail Anghel, Andrei Racautanu, email: racautanu.andrei.nicolae@info.uaic.ro Computer Science Faculty, “Al. I. Cuza” University, Iasi, Romania. (Internet sources) https://www.welivesecurity.com/wp-

content/uploads/2018/10/ESET_Ransomware_Enterprise.pdf https://www.sophos.com/en-us/medialibrary/PDFs/technicalpapers/sophoslabs-Ransomware-behavior-report.pdf

https://www.kaspersky.co.in/resource-center/threats/how-to-preventRansomware

https://phoenixnap.com/blog/preventing-detecting-Ransomware-attacks https://www.csoonline.com/article/3287099/10-ways-to-prevent-detectand-recover-from-Ransomware-and-zeroday-threats.html https://www.backblaze.com/blog/complete-guide-Ransomware/ https://enterprise.comodo.com/different-types-of-Ransomware.php

\section{AUTHORS PROFILE}

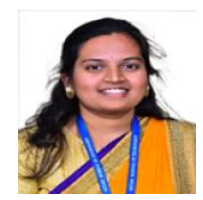

Ranjitha V., is with Computer Science and Engineering department, GITAM University, Bangalore campus. Currently she is Assistant Professor, Her areas of interest are Cyber Security, IOT, Machine learning, Big data, Networking, 5G Technologies. She can be reached at ranjithapriu@gmail.com 